\title{
Is delivery with no one present linked to other health care risks across the maternal and child health continuum in northwest zone of Nigeria? clues from the demographic and health survey
}

\author{
Bolaji Fapohunda ${ }^{1}$, Nosakhare Orobaton ${ }^{2,3}$, Kamil Shoretire ${ }^{3} \&$ Goli Lamiri ${ }^{3}$ \\ 1John Snow Research and Training (JSI R\&T), Boston, MA; USA \\ ${ }^{2}$ International Division, John Snow, Inc.; Rosslyn, VA 22209; USA \\ ${ }^{3}$ Targeted States High Impact Project (TSHIP), Bauchi and Sokoto States, Nigeria \\ Bolaji.Fapohunda8@gmail.com
}

\begin{abstract}
Information is scarce on how women who delivered with no one present (NOP) have fared in the continuum of care through the first 1000 days after birth. This study examines whether women who deliver with NOP were more likely to underutilize other $\mathrm{MNCH}$ services compared to women who delivered with attendants. This question was assessed in a sample of 5,619 currently married women aged 15-19 years, resident in the Northwest Zone of Nigeria who have had at least a live birth. The sample was obtained from the 2013 Nigeria Demographic and Health Survey (NDHS). The study revealed that women that delivered with NOP were also likely to significantly underutilize $\mathrm{MNCH}$ services across the continuum of care. To accelerate progress in $\mathrm{MNCH}$ outcomes in Nigeria, it is recommended that policy and program efforts be designed to address the underlying drivers of inequality in access to $\mathrm{MNCH}$ care.
\end{abstract}

Key words: Nigeria; delivery-with-no-one-present; maternal-newborn-child-health; skilled-birth attendance, health-care-risks; Demographic-and-Health-Survey

\section{Introduction}

It is well established that the delivery of babies with skilled birth attendants (SBA) is strongly associated with lower neonatal and maternal mortality (WHO et al, 2012; Bhutta et al 20I0; Limwattanon et al, 20I I; Nyango et al, 20l0; Barros et al, 20l2; Olusanya et al, 20I I). Skilled birth attendance (SBA), which is the proportion of all births attended by SBA is a globally accepted indicator to monitor national and global progress in maternal and health outcomes (United Nations, 20II). Table I shows SBA from selected areas of the world in relation to rates in Nigeria. Nigeria's SBA rate of $39 \%$ is considerably lower than developed economies with near universal SBA rates (99\%), North Africa (8I\%) and Sub-Saharan Africa (46\%). Sub-nationally in Nigeria, SBA rates at some zonal and state levels are much lower than rates at the national level: $20 \%$ in the Northeast, $12 \%$ in the Northwest, and $5 \%$ in Sokoto State. Five of the seven states in the Northwest each had SBA rates of less than $10 \%$. These low SBA rates correlate with Nigeria's high maternal mortality ratio (MMR) (Wakabi, 2013). As shown in Table I, the geographic areas with the highest prevalence of SBA were also the ones with the lowest MMR. The immediate causes of delivery-related fatalities are hemorrhage, infection, hypertensive disorders during pregnancy, obstructed labor, ruptured uterus, and anemia (Fubara et al, 2007, Umeora et al, 2010; Prata et al, 2012; Eze et al 2012). Indirect causes included substandard care and poor knowledge of danger signs in pregnancy, leading to delays in seeking care (Ozumba et al, 2008). These causes are compounded by using unskilled attendance or NOP at birth. Other indirect causes are few available health facilities within reasonable commuting distance; young age at birth, short birth intervals, household financial constraints, political conflicts and industrial actions (Ozumba et al, 2008; Hogan et al, 2010; Sadoh et al, 2008). The latter exacerbates the non-availability of health facilities.

Informal sector birth practitioners and mothers who deliver themselves with NOP are not technically competent; many depend on practices learned from their parents and kinsmen, others operate by trial and error. One study showed that $44.3 \%$ of traditional birth attendants (TBA) in Rivers State, Nigeria, had no formal education and $31.4 \%$ only had primary education (Ekanem et al, 2008). In Lagos State, only $8 \%$ of practicing TBAs had good knowledge about the prevention of mother-to-child 
transmission (PMTCT) of HIV (Bassey et al, 2007; Enwereji et al, 20l0). With limited to none to obsolete or no training, TBAs had no knowledge of how to manage delivery-related complications. When problems arose, poor management and delays in referral make fatal outcomes inevitable (Abodunrin et al, 2010; Abimbola et al, 2012). A hospital-based study in Calabar, Nigeria, found that of the 972 deliveries taken by TBA, 64 neonates died within the first month of life alone (Udo et al, 2008). Experts have recognized the association between TBA practices and higher rates of newborn and maternal mortality, and have called for more effective TBA training.

If TBA is a major risk factor, then delivery with NOP constitutes an emergency. Studies of why women deliver with NOP revealed that low quality of formal delivery care is a key factor. Several studies have shown that delivery care units in public health facilities in Nigeria lacked the appropriate infrastructure, equipment, good referral system and adequate human resource. The problem is intensified by facility staff that are poorly skilled, uncompromising, harsh and abrasive (Erim, et al, 20I2; Akin-Otiko et al, 20l3). For instance, Nyango and others observed that PHCs in North Central Nigeria did not have essential equipment, standard infrastructure, or skilled staff. Ninety-four percent (94\%) of the staff in the facilities they studied did not know EmOC standards, signs of clinical anemia in pregnancy, signs of pre-eclampsia, signs of obstructed labor; they also possessed no knowledge on the use of manual vacuum aspirators or a partograph. Similar weaknesses were observed among staff in maternity wards in secondary level health facilities in other parts of Nigeria (Nyango et al, 2010; lyaniwura et al, 2009; Monjok et al, 2010; ljadunola et al, 2010; Abodunrin et al, 2010; MEASURE Evaluation, 2013). Service provision are also hindered by perennial stock-out of essential drugs; a recent study showed that, at least $58 \%$ of the health facilities across 18 States in Nigeria had run out of essential drugs at any given point in time (MEASURE Evaluation, 2013). Perenial stock-out have been linked with the culture of little or nonuse of health management information for forecasting and drug logistics management (Aqil et al, 20I I).

Overall and irrespective of the weaknesses in formal health care, the evidence still indicates that facility-based delivery remains the best stratagem for reducing fatal delivery outcomes, and should be prioritized over home deliveries with skilled assistants, home deliveries with unskilled assistants, and deliveries with NOP. Empirical evidence has shown that expectant mothers in areas of southern Nigeria will do everything to ensure that they deliver with skilled attendants. For example, in the South East, some mothers concurrrently registered their pregnancy in two or more health facilities to increase the odds that at least, one facility would be readily available for them at the time of delivery (NwoguIkojo et al, 2010). In contrast, mothers from the Northwest Zone resorted to delivery with unskilled attendance or with NOP.

In this paper, we postulate that $\mathrm{MNCH}$ related risks were more highly concentrated in women who deliver with NOP, relative to those using other types of delivery attendants and that a pattern of excess risk in this class of women persisted in subsequent use practices of $\mathrm{MNCH}$ services across the continuum of care. We examined the potential concentration of risks among women who delivered with NOP through the lenses of one region (Zone) in Nigeria, the Northwest. The specific $\mathrm{MNCH}$ related practices studied were contraceptive use, ANC practices, postnatal care (PNC) practices, including PNC checkup for new mothers, child feeding, management of fever and diarrhea diseases in children under five years, and child health care record keeping.

\section{Data and Methods \\ The Settings}

The study was situated in northwestern Nigeria, consisting of seven contiguous states of the Northwest Zone: Sokoto, Zamfara, Katsina, Jigawa, Kano, Kaduna, and Kebbi States. These states are predominantly populated by Hausa and Fulani ethnic groups, $99 \%$ Muslim and rural. Eighty-four percent of the population is in the bottom three wealth quintiles; the median number of years of education was zero for both men and women alike. More than one in four women reported that they delivered their last births with NOP. The region had the lowest SBA rate of all regions in Nigeria. Seventy-four percent of the population was not literate compared with $46 \%$ nationally. The zone had a TFR of 6.7, a neonatal mortality rate (NMR) of 44 deaths per 1000 live births and infant mortality rate (IMR) of 89 deaths per 1000 live births according to the 2013 NDHS report (National Population Commission et al, 20I4).

\section{Data Collection}

Study data were obtained from the 2013 NDHS; a standard population and health outcome survey conducted among women 15-49 years and men 1559 years every five years since 1990. The 2013 survey was designed to yield representative samples at the national, zonal/regional and state levels, respectively. A detailed description of the data collection method is described elsewhere (Fapohunda et al, 2013). Briefly, women that had 
given birth in the five years preceding the survey were questioned about maternal, newborn, child health seeking practices, including place and type of delivery assistance in respect of deliveries they had had in the most recent five years. Consequently, we pooled all currently married women who had a live birth in 5 years preceding the survey. All women (438) with missing information on the key variables were excluded from the analysis. The final sample consisted of a total of 5,619 unweighted currently married women aged 15-49 years with at least one live birth.

\section{Data Analysis}

Study data were analyzed using STATA statistical package version 12 (Stata Corp., 2012). Estimates of types of delivery assistance utilized by women in five years preceding the survey were disaggregated by demographic, socioeconomic, and women's autonomy characteristics. Frequencies were used to describe the profiles of NOP and the propensity of women already using NOP to also underutilize other protective $\mathrm{MNCH}$ practices. To confirm observations at the bivariate level, logistic regressions were used to elaborate the integration of risks among the women who utilized NOP versus those that utilized skilled attendance in the study population. Three domains of covariates were controlled in the multivariate analysis: demographic characteristics, women's social autonomy and economic security domains. The latter was indicated by women's education level and wealth quintile. Three models were presented. The first examined the association between the risk factors and NOP controlling for the social context of women's lives, indicated by State membership, and women's age. Model 2 presented the effects of demographic, women's autonomy and economic security variables. The final and full Model, Model 3, combined indicators from Models I \& 2.

The selection of variables included in the model was guided by an underlying theory of change and knowledge of the social context. In our theory of change, we assumed that the concentration of risks in women who delivered with NOP relative to those who sought other types of delivery assistances was influenced by population age structure and state of residence. Based on this assumption, we controlled for mother's age and state of residence in all three models and presented adjusted odds ratios. All estimates and differentials were assessed for statistical significance at the .01 alpha level and variables were retained in the analysis if they were statistically significant. Sample weights were used to control for over- or under-sampling within groups.

Details of variables employed in the analysis are presented in Table 2. In brief, the outcome measure was coded I if a woman delivered her last births with NOP versus other methods (SBA or unskilled attendants). The use of $\mathrm{MNCH}$ services across the continuum of care in the most recent pregnancy associated with delivery, immediate PNC period and beyond that were examined with seven indicators, namely:

I) mothers contraceptive practice;

2) antenatal care attendance (ANC) during pregnancy of at least four visits;

3) postnatal care checkup for women within two months following delivery per policy;

4) breastfeeding initiation within the first hour after delivery;

5) exclusive breastfeeding of the last birth within the first three days of life;

6) ITN ownership, and

7) home management of diarrhea in children U5.

In addition, we examined the incidence of fevers of which malaria is a principal cause to indirectly understand the patterns of health care seeking for children who might have been infected by the plasmodium falciparum, the parasite that causes malaria (International Med Corps, 2015). As with other indicators, we sought to understand to which extent mothers who utilized NOP attendance were likely to present children with fever for treatment and what type of services, public or private, were preferred. The result is presented in Table 4.

To explain the magnitude of the risk of underutilization of services associated with use patterns of $\mathrm{MNCH}$ services across the women, we summarized the risk indicators into an interval level data with scores corresponding to the number of risky practices per woman. For example, women with zero score on the interval level measure were those whose $\mathrm{MNCH}$ care practices were fully compliant with recommended $\mathrm{MNCH}$ standards. Women who scored one practiced one thing incorrectly, those who scored two practiced two things incorrectly and so on. We summarized the scores into average number of risky practices by type of delivery attendance in the most recent delivery using ordinary least squares regression procedure. The result is presented in Figure I.

The Nigeria DHS 2013 survey was approved by the Ethics Committee of the ICF Macro at Calverton in the USA and by the National Ethics Committee in the Ministry of Health in Nigeria. To secure participants' consent, an informed written consent statement was designed and attached to each individual interview. The statement was read individually to all respondents prior to the interview. Only participants that gave written consent participated in the survey. 


\section{Results}

Table 3 presents the socioeconomic distribution of married women whose last births occurred in five years preceding the survey. Ninety-two and half percent $(92.5 \%)$ of these women were from Muslim households and $7.5 \%$ were affiliated with other religions. The women were young with more than half of the entire sample aged 15-29 years. Another $18.6 \%$ were in the $30-34$ age group and $12 \%$ were aged 40 years and above. On average, the women had 5 children of which about 4 were alive at the time of the survey. Roughly four in five women had no formal education, resided in rural areas, and lived in poorer households. On women's autonomy, slightly less than half of the women were in polygynous unions. Majority of them worked and earned cash for work (60\%); majority were involved in household level decision making (66.2\%); and majority (over $70 \%$ ) rejected intimate partner violence (IPV) under any of the measured conditions. Except for Kano State with one fourth of the entire sample, the women appeared to be evenly distributed across the States. On the type of delivery attendants utilized in the most recent delivery, $28 \%$ of the women reported that they delivered with NOP, $31 \%$ with TBA, $26 \%$ utilized other unskilled assistants and 15\% utilized skilled assistants (Table 3).

In Table 4, we confined the analysis of differentials in the utilization of $\mathrm{MNCH}$ practices to the subsample that practiced NOP and those who utilized skilled birth attendants during their last deliveries. As shown in Figure I, women that delivered with NOP were less likely to be using contraception (I3.3\% reported use of any method), less likely to have postnatal check (1 I.4\% were checked following last delivery); more likely to feed their newborn foods or liquids instead of breast milk exclusively within first 3 days of life (71.6\%); more likely to report diarrhea in children $(64 \%)$ and less likely to report that their sick children received antibiotics for diarrhea (39.4\%). In contrast, $80.7 \%$ of those who delivered with SBA used contraception; $88.6 \%$ received post-natal check-up after their last deliveries. In addition, more than half $(53.5 \%)$ put their babies to the breast in their first hour of delivery, $60.6 \%$ gave antibiotics to children who had diarrhea disease within two weeks preceding the survey and only $28.4 \%$ fed something other than breast milk to their newborns in their first three days of life.

On the management of fever, Table 4 showed that, $13.2 \%$ of the women reported that their children had fever and most of these were children delivered with NOP (62\%). Large numbers of women who delivered with NOP either sought treatment for children with fever from shops/medicine hawkers (74\%) and/or traditional healers (84\%). In contrast, only $25.6 \%$ and $14.6 \%$ of women whose last deliveries were attended by SBAs sought care for children with fever from these informal sources.

We observed a clustering of risks linked to a pattern of underutilization of $\mathrm{MNCH}$ services among women that delivered with NOP. The analysis presented in Figure I illustrates the depth of risk. As shown, the number of instances of under use of $\mathrm{MNCH}$ practices by the women ranged from 4 to 7 ; 4.5 among women who utilized SBA, 7.2 among those who utilized unskilled attendants, and 7.4 among women who delivered with NOP. The model was statistically significant $(F 2,5616=1212.56, p<$ .01 ) and type of delivery attendant alone explained $30.2 \%$ of the variability in the magnitude of risk associated with maternal and newborn practices among the women.

\section{Results of the Multivariate Analysis}

The results of the multivariate analysis are presented in Table 5. Three models are presented. The first consists of the $\mathrm{MNCH}$ risk indicators. The second consists of the socioeconomic covariates and the third is the full model with both the socioeconomic and $\mathrm{MNCH}$ risk factors combined. In each model, we controlled for women's age and state of residence.

Model I showed that all the measured risk factors were significantly associated with NOP deliveries. Women who delivered with NOP had $44 \%$ higher odds of not using contraception and $15 \%$ higher odds of not seeking ANC; $364 \%$ higher odds of not receiving post-natal check-up and $55 \%$ higher odds of not initiating breastfeeding within the first hour of life compared to their peers who utilized any attendants, be they skilled or unskilled, in their last deliveries. The analysis revealed further that women who delivered with NOP had $20 \%$ higher odds of not acquiring a health card for record keeping in regard of their U5 health; $32 \%$ higher odds of feeding their babies foods/liquids other than breast milk in the first three days of life; and 68\% higher odds of reporting a diarrheal disease in their U5 in two weeks prior to the survey. Of those who reported a diarrhea disease, women who delivered their last birth with NOP had $200 \%$ higher odds of not presenting those children for treatment with antibiotics than mothers whose births were attended by any attendants. These relationships were significant at the $.0 \mathrm{l}$ alpha levels.

Model 2 presents the analysis of the socioeconomic factors on the type of delivery attendant utilized in the most recent deliveries. As shown, having limited or no education, being in the three lowest wealth quintiles, and being Muslim were 
associated significantly with higher odds of NOP attendance. On women's autonomy, we found that women who were in polygynous unions, who were not involved in decision making, that approved of wife beating if the wife went out without their husband's prior permission - fit the profile of having weak social autonomy - had higher odds of delivering with NOP than mothers who had high social autonomy. Two dimensions of weak autonomy: I) lack of access to cash income and 2) approval of wife beating if the wife refused to have sex with her husband, measures expected to leverage NOP, prevented it as shown in Table 5. Older women were more likely to deliver with NOP than younger women and residency in rural areas prevented rather than promoted NOP.

These high odds of women that delivered with NOP also being more likely to opt for lower uptake of protective $\mathrm{MNCH}$ behaviors remained strong even after socioeconomic and contextual covariates were accounted (Model 3). One interesting finding is the very large between-State differentials in the level of uptake of protective $\mathrm{MNCH}$ practices associated with NOP in the region. As shown in Table 5, women who lived in Zamfara State or Kano State had at least five times higher odds of delivering their last birth with NOP than their peers who lived in Sokoto State. Women in Katsina, Kebbi, Jigawa and Kaduna States were nearly twice as likely to deliver their last births with NOP as those in Sokoto. As shown in the discussion section, these effects probably captured differentials in programme effort between these States.

\section{Discussion}

Women that delivered with NOP were also likely to underutilize $\mathrm{MNCH}$ care practices across the continuum of care. These women were less likely to use contraception, less likely to initiate breastfeeding immediately following delivery, less likely to breastfeed their newborn exclusively even in the Ist three days of life, less likely to have health cards for monitoring children's health, and less likely to seek an appropriate care for sick children. The consistent pattern of under-utilization of $\mathrm{MNCH}$ services by women who deliver with NOP suggests that these women and their offspring were a uniquely vulnerable group with higher health disparities.

In accord with evidence documented in women's status literature (Wodemicael et al, 20 I0; Kritz et al, 1999; Bankole 1995), improvements in women's social autonomy that would catalyze improvements in $\mathrm{MNCH}$ must improve women's access to care, strengthen their economic security so that they are effectively able to demand services, and raise their consciousness about appropriately using services.
These improvements would enhance women's capabilities to tap information already within their reach to alter health seeking behavior in ways that would enhance their own health, the health of their children, and the health of their communities. Although we found no major differences in demand for NOP among women who worked for cash versus those who worked for in-kind payment in this study, women who had access to cash payment were more likely to demand SBA than those working for in-kind payment. Therefore, as women become fully integrated into the cash economy, the transformative effects of better access to economic power, under good governance, could translate into greater demand for protective $\mathrm{MNCH}$ care.

Given that women's social autonomy is multidimensional and intricately woven into the cultural milieu, this study shows that improvement in one element may not necessarily translate into better decision-making power overall. Improvements in conditions of women's lives must be multipronged to make a lasting difference in women's health outcomes. For instance, we found that approval of violence against wives who refused to have sex with her husband, a measure expected to promote NOP appeared to prevent it (Table 5). Programmes need to carefully consider which aspects of women's autonomy to address to truly realize better health behavior outcomes. While improving women's ability to negotiate sex is important, it may not automatically confer women with the ability to negotiate other aspects of health such as use of skilled birth attendance. In this study, we found that the litmus test of spousal autonomy did not rest with a wife's ability to successfully refuse sex with her husband. Rather, it depended on her capacity to overcome the imposition of the restriction placed on her physical movement. Programmes that seek to improve women's status and reduce NOP will be most effective when women achieve greater freedom of movement.

Finally, we learned that although context matters in $\mathrm{MNCH}$ outcomes, programme efforts matter even more. A well-planned community-based intervention can transform the most restrictive of contexts into favorable outcomes with reduced NOP and increased demand for $\mathrm{MNCH}$ services. The major decline in the prevalence of NOP in Sokoto State compared with other states in the NW is illustrative of this point. Of these States, Sokoto appeared to have had much longer history of $\mathrm{MNCH} / \mathrm{RH}$ interventions. Dating back to the late 80 s with the implementation of Basic support for institutionalizing child health (BASICS) to the most recent programme, TSHIP, a period spanning roughly 21 years, USAID had funded a series of high impact community-based 
programmes proven to improve $\mathrm{MNCH}$ outcomes in the Nigeria region. Of the seven States in the NW, only Sokoto State had an uninterrupted involvement in these interventions. In addition, as one of the two States implementing the USAID-TSHIP Programme, Sokoto State is a beneficiary of recent communitybased interventions, which placed community-based health volunteers (CBHVs) in households at the point of delivery to accompany women who were about to deliver their babies. These $\mathrm{CBHVs}$ also distributed life-saving commodities, misoprostol and chlorhexidine, respectively, to women in labor for the treatment of post-partum hemorrhage and cord sepsis, two leading killers of new moms and newborns in Nigeria. This CBHV programme was a key contributor to the decline in the prevalence of NOP from $25 \%$ to less than $1 \%$ between 2008 and 2013 (Orobaton et al, 2016). Otherwise, Sokoto and the other six NW States had similar social, cultural, educational, economic and religious infrastructure. Health care seeking practices should, therefore, have been at the same level in all six States if programme effort had not made a major difference in $\mathrm{MNCH}$ outcomes between the States. This finding-of a large and significant effect of state of residence on $\mathrm{MNCH}$ care seeking - suggests that a focused study of programme effort in these States would be useful in accounting for returns to investments in the communities and for identifying scalable actions for eradicating NOP in the region. With dedicated government leadership and strong community engagement, the current NOP delivery practices and associated inequities in the region could be rapidly overcome.

In the short term, we recommend that state governments need to urgently find ways to assist resource-challenged mothers currently using risky modes of delivery attendances to make the switch to skilled care. One potential programme, which has been proven to work in many resource-poor settings and those with extreme poverty, is the use of conditional cash transfers to defray the cost of health care (Fernald et al, 2008; Lagarde et al, 2007; Glassman et al, 2013; Okoli et al, 2014). Application of this programme, currently being tested in many states in Nigeria, including states in the Northwest, involves putting actual cash in the hands of expectant mothers to subsidize costs of care, mother's transportation costs for health facility visits and cost of medicines. A recent evaluation shows that this programme is working but is fraught with problems. One key problem is high dropout rate by women who have received initial funding; about $35 \%$ of these women did not return to the programme (Okoli et al, 2014). A more sustainable instrument in how women seek care might be to install universal health insurance coverage of households, particularly for maternal, newborn and child health services to eliminate financial barriers to using health facilities for delivery care. Universal coverage will empower women and their families to increase their demand for $\mathrm{MNCH}$ services without facing the risk of running out of resources to pay for them. To sustain the potential increases in service utilization that this instrument is likely to engender, accelerated improvements in the availability of skilled health personnel to operate health facilities is warranted. The thriving Midwifery Service Scheme (MSS) championed by the Federal Government or some equivalent needs to be expanded through substantially higher state government-led investments. This also includes the scale up of community midwives training programme to ensure the availability of skilled manpower particularly in health facilities where EmOC services are lacking. The scale up of successful community-based $\mathrm{MNCH}$ programmes will be pivotal for increasing coverage with skilled delivery services and eradicating NOP and associated health outcomes.

Contrary to expectation, the multivariate analysis revealed that women resident in rural areas of this region had far less odds of delivering with NOP than their counterparts in the urban area. This effect may be due to the absence of the basic amenities in the urban areas, e.g. lack of infrastructure, portable water, education, health care, good network of roads, etc. With the lack of these basic amenities, the urban residence is nominal rather than transformative in empowering women to make better health care choices. People in rural areas may fare better than those in the urban areas because they live closer to a spring or a well and have kerosene in their lamps and can easily access these resources. Unmet expectations arising from increased cost of living in the urban place with no compensatory returns in terms of access to basic functional amenities could intensify conservatism and increase the willingness by urban residents to forgo rational thinking in favour of what works.

\section{Conclusion}

The study found significant relationship between high prevalence of NOP (accounting for $28 \%$ of all live births per year in NW, Nigeria) and the persistence of underutilization of $\mathrm{MNCH}$ practices across the continuum of care among mothers practicing NOP. Women who delivered their most recent births with NOP were less likely to use contraception, less likely to initiate breastfeeding immediately following delivery, less likely to breastfeed their newborn exclusively even in the Ist three days of life, less likely to have health cards for monitoring children's health, 
and less likely to seek an appropriate care for sick children. Inequities in access to resources is a key lever for the underutilization of protective $\mathrm{MNCH}$ services and practices among women who deliver with NOP. Mothers who delivered with NOP qualify to be treated as a uniquely vulnerable group who are likely to contribute disproportionately to maternal and newborn morbidity and mortality levels. Although context could pose a major challenge in instituting a change in the prevalence of NOP, the case of Sokoto State demonstrates that well-designed programmes can engineer a transformation in maternal health care practices even in the most restrictive environment (National Population Commission, et. al. 20l4, Orobaton et al, 2016). Therefore, a well-designed programme with good governance is urgently needed to eradicate NOP and its associated risks in northwestern Nigeria.

\section{Competing Interests}

The authors declare that they have no competing interests. All four authors were employees of John Snow, Inc. (JSI), which is a commercial private company, at the time the article was prepared. JSI fully support policies relating to publicly sharing research findings and information for the common good and so do the authors. Their involvement with JSI, therefore, did not alter adherence to all the relevant policies on sharing data and materials.

\section{Authors' Contributions}

All authors, BM, NO, KS, and GL contributed sufficiently to the manuscript. Unfortunately, GL passed away after a brief illness while this paper was undergoing peer review at the APS. Therefore, he was unable to participate in the final revision of this paper. The technical content was, however, the exact same version approved by all four authors before GL's death. The manuscript has never been published and is not scheduled for publication anywhere else.

\section{Acknowledgements}

The authors are grateful to I) Dr. Dele Abegunde, USAID/TSHIP Director of M\&E, for review and comments; 2) Mr. John Carper, Librarian, JSI, for his assistance and support in gathering scientific materials that formed the basis for the literature review and background for this work, and 3) Mrs. Iroayo Yewande Olorunnipa for reviewing and editing drafts of the paper.

\section{References}

Abimbola S, Okoli U, Olubajo O, Abdullahi MJ, Pate MA. 2012. The Midwives service scheme in Nigeria. PLoS Medicine 5 (9): I-4.

Abodunin OL, Akande TM, Musa IO, Aderibigbe SA. 2010. Determinants of referral practices of

clients by traditional birth attendants in Ilorin, Nigeria. Afr J Reprod Health 14: 77-84.

Akin-Otiko BO, Bhengu BR. 2013. Client education experiences and expectations of women at the Ist level of maternal and child care in Kaduna State, Nigeria. Midwifery [Epub].

Aqil A, Lippeveld T, Hozumi D. 20II. PRISM framework: a paradigm shift for designing, strengthening and evaluating routine health information systems. Health Pol Planning 24:217228.

Bankole A. 1995. Desired fertility and fertility behaviour among the Yoruba of Nigeria: A study of couples' preferences and subsequent fertility. Population Studies 49:317-28.

Barros AJ, Ronsmans C, Axelson H, et al. 2012. Equity in maternal, newborn, and child health interventions in Countdown to 2015: a retrospective review of survey data from 54 countries. Lancet 379: 1225-33.

Bassey EB, Elemuwa CO, Anukam KC. 2007. Knowledge of, and attitudes to, acquired immune deficiency syndrome (AIDS) among traditional birth attendants (TBAs) in rural communities in Cross River State, Nigeria. Int. Nurs Rev. 54: 3548.

Bhutta ZA, Chopra M, Axelson H, Berman P, et al. 2010. Countdown to 2015 decade report (200010): taking stock of maternal, newborn, and child survival. Lancet 375: 2032-2044.

Ekanem El, Etuk SJ, Ekott MI, Ekabua JE, Iklaki C. 2008. Socio demographic profile and presentations of parents with ruptured uterus in Calabar Nigeria. Niger J of Medicine 17: 78-82.

Enwereji EE, Enwereji KO. 20I0. Assessing factors that affect childbirth choices of people living positively with HIV/AIDS in Abia State of Nigeria. Oman Med J. 25(2):91-99.

Erim DO, Kolapo UM, Resch SC. 2012. A rapid assessment of the availability and use of obstetric care in Nigerian healthcare facilities. PLoS One 7 (6): e39555.

Eze JN, lbekwe PC. 2010. Uterine rupture at a secondary hospital in Afikpo, Southeast Nigeria. Singapore Med Journal 5I: 506-II.

Fapohunda B, Orobaton N. 2013. When women deliver with no one present in Nigeria: who what, where and so what? PLoS ONE 8 (7): I-I 2.

Fernald CH, Gertler PJ, Neufeld LM. 2008. Role of cash in conditional cash transfer programmes for 
child health, growth, and development: an analysis of Mexico's Oportunidades. Lancet 37I: 828-3.

Fubara DS, Ikimalo J, John CT. 2007. Pathology of maternal deaths in Rivers State: a ten year autopsy review in a referral hospital. Niger Postgrad Med J. 14 (3):256-60.

Glassman A, Duran D, Koblinsky M. 2013. Impact of conditional cash transfer on maternal and newborn health. CDG Policy Paper 019 [http://www.cgdev.org/sites/.../impactconditional-cash-transfer-health_0.pdf]

Grünebaum A, McCullough LB, Sapra KJ, et al. 20I3. Apgar Score of 0 at 5 minutes and neonatal seizures or serious neurologic dysfunction in relation to birth setting. American J of Obstetric \& Gynecology 209: 323.el-6.

Hogan MC, Foreman KJ, Naghavi M, et al. 2010. Maternal mortality for I8I Countries, 1980-2008: a systematic analysis of progress towards Millennium Development Goals 5. Lancet 375: I609-I623.

ljadunola KT, ljadunola MY, Esimai OA, Abiona TC. 2010. New paradigm old thinking: The case for emergency obstetric care in the prevention of maternal mortality in Nigeria. BMC Women's Health 17: 10:16.

International Medical Corps. 2017. Malaria [Webpage on the internet]. Available from http://internationalmedicalcorps.org/page.aspx?pid $=501$ \&gclid $=$ CNb2tZb82bgCFQSk4AodlxMA. Accessed February 12, 2017.

lyaniwura CA, Yussuf Q. 2009. Utilization of antenatal care and delivery services in Sagamu, south western Nigeria. Afr J Reprod Health |3: | | |-22.

Kritz M, Makinwa-Adebusoye P. 1999. Determinants of Women's Decision-Making Authority in Nigeria: The Ethnic Dimension. Sociological Forum (1999) 14: 399.

Lagarde M, Haines A, Palmer N. 2007. Conditional cash transfers for improving uptake of health interventions in low- and middle-income countries: a systematic review. JAMA 298: 190010.

Limwattananon S, Tangcharoensathien V, Sirilak S. 20ll. Trends and inequities in where women delivered their babies in 25 low-income countries: evidence from Demographic and Health Surveys. Reprod Health Matters 19: 75-85.

MEASURE Evaluation. 2013. Assessment of primary health care facilities for decentralization of HIV/AIDS services in Nigeria. MEASURE Evaluation Technical Report. Charlotte, NC: MEASURE Evaluation.
Monjok E, Essien EJ, Smesny A, Okpokam SN. 2010. A training need for rural primary care in Nigeria. J Obsteric and Gynaecol 30 (8):883-5.

National Population Commission (NPC) [Nigeria] and ICF International. 20I4. Nigeria Demographic and Health Survey, Abuja, Nigeria. Available from http://dhsprogram.com/pubs/ pdf/FR293/FR293.pdf.

Nyango DD, Mutihir JT, Laabes EP, Kigbu JH, Buba M. 20I0. Skilled attendance: the key challenges to progress in achieving MDG-5 in north central Nigeria. Afr J Reprod Health I4: 129-38.

Nwogu-lkojo EE, Okafor II, Ezegwui HU. 2010. Multiple antenatal bookings among pregnant women in Enugu, Nigeria. Journal of Obstet Gyneacol 3:244-7.

Okoli U, Morris L, Oshin A, Pate MA, Aigbe C, Muhammad A. 20I4. Conditional cash transfer schemes in Nigeria: Potential gains for maternal and child health service uptake in a national programme". BMC Pregnancy and Childbirth 14: 408-4I 3.

Olusanya BO, Inem VA, Abosede OA. 20II. Infants delivered in maternity homes run by traditional birth attendants in urban Nigeria: a communitybased study. Health Care Women Int. 32:474-9I.

Orobaton N, Austin A, Fapohunda B, Abegunde D, Omo K. 2016. Mapping the prevalence and sociodemographic characteristics of women who deliver alone: evidence from Demographic and Health Surveys from 80 Countries. Global Health Science and Practice 4 (I): 99-I I 3

Ozumba BC, Nwogu-lkojo EE. 2008. Avoidable maternal mortality in Enugu, Nigeria. Public Health I22: 354-60.

Prata N, Ejembi C, Fraser A, Shittu O, Minkler M. 2012. Community mobilization to reduce postpartum hemorrhage in home births in northern Nigeria. Soc Sci Med. 74: I 288-96.

Sadoh AE, Ogungbe RO. 2008. Multiple fractures and iatrogenic burns in a newborn due to unskilled delivery: a case report. Afr J Repro Health 12(3): 197-206

Singh K, Bloom S, Haney E, Olorunsaiye C, Brodish P. 2012. Gender equality and childbirth in a health facility: Nigeria and MDG5. Afr J Reprod Health. 16:122-128.

Stata Corp. 2012. Stata 12. College Station, Tx: StataCorp LP.

Udo JJ, Anah MU, Ochigbo SO, Etuk IS, Ekanem AD. 2008. Neonatal morbidity and mortality in Calabar, Nigeria: a hospital-based study. Niger J Clinc Practice II: 285-9

Umeora OU, Egwuatu VE. 2010. The role of unorthodox and traditional birth care in maternal mortality. Trop Doct. 40: I3-7. 
United Nations: 20I I. The Millennium Development Goals Report. NY: UN.

Wakabi W. 2013. Nigeria aims to boost fight against maternal mortality. Lancet 38I: 1708.
WHO, UNICEF, UNFPA, 20I2. The World Bank: Trends in Maternal Mortality: 1990-2010. Geneva: WHO.

Woldemicael, G. \& Tenkorang, E.Y. 20I0. Women's autonomy and maternal health-seeking behavior in Ethiopia. Matern Child Health J 14: 988.

\section{TABLES}

Table I: Skill delivery attendance (SBA) coverage and maternal mortality ratio (MMR) in selected regions and Nigeria

\begin{tabular}{|c|c|c|c|}
\hline \multirow[b]{2}{*}{ Region } & \multirow{2}{*}{$\begin{array}{c}\text { Maternal deaths per } 100,000 \\
\text { live births (MMR): } \\
2010^{+} \\
\end{array}$} & \multicolumn{2}{|c|}{$\begin{array}{l}\text { \% of deliveries attened by skilled birth } \\
\text { attendants (SBA): }\end{array}$} \\
\hline & & $1990^{++}$ & $2009^{++}$ \\
\hline World & 210 & 42 & 46 \\
\hline Developed regions & 16 & 99 & 99 \\
\hline Developing regions & 240 & 55 & 65 \\
\hline Western Asia & 71 & 40 & 78 \\
\hline Latin America & 72 & 70 & 90 \\
\hline Sub-Saharan Africa & 500 & 42 & 46 \\
\hline Northern Africa & 78 & 45 & 81 \\
\hline $\begin{array}{l}\text { Nigeria MMR } 2013 \text { - Nigeria } \\
\text { Source: WHO, UNICEF, The } \\
\text { The Millennium Developmen } \\
\text { at } 38.1 \% \text { nationally. }\end{array}$ & $\begin{array}{l}576^{*} \\
\text { Trends in maternal mortality: } \\
\text { ort 20I I. UN: NY, p. } 29^{++} .{ }^{*}\end{array}$ & $\begin{array}{c}35.2 \\
\text { to } 2010 . \text { Gen } \\
\text { 20।* Rate }\end{array}$ & $\begin{array}{l}38.9^{* * *} \\
53^{+} . \text {UN }(201 \\
\text { changed in } 20\end{array}$ \\
\hline
\end{tabular}

Table 2: Description of predictor and outcome variables

Variables
Health seeking behavior risk measures
$\begin{aligned} & \text { Type of delivery } \\ & \text { assistance }\end{aligned}$
$\begin{aligned} & \text { Categorical variable measuring the type of delivery assistant that women utilized for their last } \\ & \text { birth in in } 5 \text { years preceding the survey (i.e. between 2008-20I3); coded I if women } \\ & \text { delivered themselves alone with NOP, } 2 \text { if they were attended by skilled birth attendants } \\ & \text { (SBA), } 3 \text { if by traditional birth attendants (TBAs), } 0 \text { if other attendants (relatives/friends). In } \\ & \text { the multivariate analysis, the variable was re-categorized into a dummy variable, coded I if } \\ & \text { women reported that they delivered their most recent children with NOP and } 0 \text { otherwise. }\end{aligned}$

Contraceptive use Dummy variable coded I if women reported using any method and 0 if using no method.

\begin{tabular}{|c|c|}
\hline $\begin{array}{l}\text { Ante-natal care }(\mathrm{ANC}) \\
\text { visits }\end{array}$ & $\begin{array}{l}\text { Categorical variable coded I if women visited I-4 times and } 2 \text { of they had } 5 \text { or more ANC } \\
\text { visits during their last pregnancy, otherwise the variable was coded } 0 \text {. In the multivariate } \\
\text { analysis, this measure was refined into a dummy variable, coded } I \text { if no visits and } 0 \\
\text { otherwise. }\end{array}$ \\
\hline Post-natal check up & $\begin{array}{l}\text { Dummy variables coded I if women reported they were checked in } 2 \text { months following the } \\
\text { birth of their last child, otherwise it was coded } 0 \text { otherwise. }\end{array}$ \\
\hline $\begin{array}{l}\text { Time women put baby to } \\
\text { breast following delivery }\end{array}$ & $\begin{array}{l}\text { Dummy variable coded I if women reported that they breastfed their newborns several } \\
\text { hours/days after delivery or not all, it was coded } 0 \text { if women reported that they breastfed } \\
\text { within the first hour per the policy. }\end{array}$ \\
\hline $\begin{array}{l}\text { Children breast fed } \\
\text { exclusively in their } 1^{\text {st }} \\
\text { three days of life }\end{array}$ & $\begin{array}{l}\text { Dummy variable coded I if women reported that they fed their newborns foods and/or } \\
\text { liquids [fed something] other than breast milk in the } I^{\text {st }} \text { three days of the newborn life and } 0 \\
\text { if they fed nothing other than breastmilk in the first } 3 \text { days following delivery. }\end{array}$ \\
\hline Children U5 slept under & Categorical variable coded I if women reported no net, 2 if they had a net but their U5 did \\
\hline http:/ & 3448 \\
\hline
\end{tabular}




\begin{tabular}{|c|c|}
\hline $\begin{array}{l}\mathrm{N} \text { in night before the } \\
\text { urvey }\end{array}$ & erwise, it \\
\hline Health card ownership & $\begin{array}{l}\text { Dummy variable coded I if women reported that their children U5 never had a health } \\
\text { card/no longer had one, otherwise it was coded } 0 \text {. }\end{array}$ \\
\hline U5 diarrhea & $\begin{array}{l}\text { Dummy variable coded I if women reported their } U 5 \text { had diarrheal in two weeks prior to } \\
\text { the survey, otherwise it was coded } 0 \text {. }\end{array}$ \\
\hline $\begin{array}{l}\text { Received antibiotics for } \\
\text { diarrhea }\end{array}$ & $\begin{array}{l}\text { Dummy variable coded I if women reported that their children who had diarrheal were } \\
\text { given NO antibiotics, otherwise it was coded } 0 \text {. }\end{array}$ \\
\hline U5 fever & $\begin{array}{l}\text { Dummy variable coded I if women reported that their U5 had fever in two weeks preceding } \\
\text { the survey, otherwise it was coded } 0 \text {. }\end{array}$ \\
\hline $\begin{array}{l}\text { Received treatment }(\mathrm{Rx}) \\
\text { for fever }\end{array}$ & $\begin{array}{l}\text { Dummy variable coded I if women reported that their U5 who had fever received NO } \\
\text { treatment, otherwise it was coded } 0 .\end{array}$ \\
\hline $\begin{array}{l}\text { Place of treatment for U5 } \\
\text { who were treated for } \\
\text { fever }\end{array}$ & $\begin{array}{l}\text { Measured using three dummy variables: I) coded I if } U 5 \text { received Rx from public health } \\
\text { facilities (PHCs/health Posts), zero otherwise; } 2 \text { ) coded I if } U 5 \text { received Rx from shops, } \\
\text { markets or patent medicine sellers (PMS), otherwise the variable was coded } 0 \text {; and } 3 \text { ) coded } \\
\text { I if } \cup 5 \text { received treatment from other sources, including traditional healers, otherwise it was } \\
\text { coded } 0 \text {. }\end{array}$ \\
\hline
\end{tabular}

\section{Socio-demographic variables}

Mothers age Measured in 5 year intervals: 15-19, 20-24, .., 40-49

Children ever born (ceb) Interval data, measuring the number of live births women ever had

CEB alive Interval data, measuring the number of live births who are alive at the time of the survey of the total ceb.

Residence (Rural/urban) Coded I if women lived in urban areas and 0 otherwise.

Education Coded lif women reported that they had some/completed primary education, 2 if women had some/completed secondary education or higher, and 0 if she had no formal education). The variable was dummy coded in the multivariate analysis: I if no education and 0 if some education,

Wealth quintiles Measured using ownership of household consumables; infrastructure (e.g. building type, water, electricity, toilet facilities); small equipment (e.g. telephone, TVs), and large equipment (bikes, cars, etc). Items were coded into a relative index of household wealth, calibrated into quintiles, each representing $20 \%$ of the score, from I (poorest) to 5 (richest) quintiles. Respondents were ranked by wealth quintiles using this index.

Religion Coded I if women reported they were Muslim and 0 if they were Christians or affiliated with other religions.

Women's autonomy Measures

Women's autonomy Represented by four indicators:

I) Current work status was coded I if women were working and receiving cash for their work and 0 if they were receiving in-kind-payment or were not working at all.

2) Decision-making power: multicategorical variable coded I if women reported that they were not involved in decision-making on any of the seven elements of household organization, expected to involve husband/wife participation: decisions regarding purchase of large household goods, purchases of daily needs, women's own health care, visits to family, food to be cooked each day, how to spend women's own income and what to do with income husbands earn. Women received a code of 2 if they were involved in decisionmaking on one or more elements, and 0 if they reported that they made all the decisions alone or in collaboration with their husbands. In the multivariate analysis, the variable was summarized into a dummy variable, coded $I$ if women said they were not involved in any decisions alone or in collaboration with their husbands, otherwise, it was coded 0 .

3) Presence of co-wives, coded I if women reported that their husbands had other wives, which means the wives were polygynously married. Otherwise, the variable was coded 0 .

4) Approval of wife beating (a.k.a intimate violence orlPV): measured using two dummy variables: I) coded I if women said yes it was ok to beat wife if she went out without telling the husband, otherwise it was coded 0.2) coded I if women said it was okay to beat wife if 
she refused sex, otherwise it was coded 0 .

Table 3: Delivery attendant utilized in the most recent deliveries by women who had a live birth in 5 years preceding the survey by socioeconomic characteristics, NW, Nigeria DHS 2015

\begin{tabular}{|c|c|c|c|c|c|c|c|c|}
\hline \multirow[t]{2}{*}{ Characteristic } & \multirow[t]{2}{*}{$\begin{array}{c}\text { Un- } \\
\text { weighted } \\
N\end{array}$} & \multirow{2}{*}{$\begin{array}{c}\text { Weighted } \\
\%\end{array}$} & \multicolumn{6}{|c|}{$\%$ delivered by specific type of delivery assistant } \\
\hline & & & NOP & TBA & $\begin{array}{r}\text { Other } \\
\text { unskilled }\end{array}$ & SBA & Total & $x^{2}$ \\
\hline \multicolumn{9}{|l|}{$\begin{array}{l}\text { Mother's age } \\
\text { at birth }\end{array}$} \\
\hline $15-19$ & 459 & 8.2 & 14.7 & 36.2 & 34.1 & 15.0 & 100 & $<.0001$ \\
\hline $20-24$ & 1181 & 21.1 & 21.3 & 33.7 & 28.9 & 16.0 & 100 & \\
\hline 25-29 & 1447 & 25.6 & 27.4 & 30.5 & 28.0 & 14.1 & 100 & \\
\hline $30-34$ & 1047 & 18.6 & 31.5 & 29.8 & 22.7 & 16.0 & 100 & \\
\hline $35-39$ & 804 & 14.5 & 32.8 & 29.8 & 22.8 & 14.7 & 100 & \\
\hline $40-44$ & 447 & 7.8 & 37.8 & 29.1 & 20.4 & 12.6 & 100 & \\
\hline $45-49$ & 234 & 4.2 & 44.1 & 23.3 & 22.9 & 9.6 & 100 & \\
\hline \multicolumn{9}{|l|}{ CEB } \\
\hline I & 792 & 14.5 & 10.7 & 36.0 & 29.7 & 23.7 & 100 & $<.0001$ \\
\hline 2 & 767 & 13.7 & 24.9 & 28.7 & 29.5 & 16.8 & 100 & \\
\hline 3 & 758 & 13.5 & 24.6 & 33.2 & 27.8 & 14.8 & 100 & \\
\hline 4 & 694 & 12.8 & 28.6 & 28.2 & 28.0 & 15.1 & 100 & \\
\hline 5 & 624 & 11.0 & 29.7 & 30.6 & 25.2 & 14.6 & 100 & \\
\hline 6 & 527 & 9.2 & 31.8 & 31.1 & 26.1 & 11.0 & 100 & \\
\hline $7+$ & 1457 & 25.2 & 39.6 & 29.8 & 20.7 & 9.7 & 100 & \\
\hline Mean CEB & 5619 & 4.6 & 5.5 & 4.5 & 4.3 & 3.9 & & \\
\hline $\begin{array}{l}\text { Mean CEB } \\
\text { alive }\end{array}$ & 5619 & 3.8 & 4.3 & 3.7 & 3.5 & 3.4 & & \\
\hline Residence & & & & & & & & $<.0001$ \\
\hline Urban & 1138 & 23.1 & 21.0 & 18.6 & 24.2 & 36.1 & 100 & \\
\hline Rural & 4481 & 76.9 & 30.2 & 34.8 & 26.7 & 8.3 & 100 & \\
\hline Religion & & & & & & & & $<.0001$ \\
\hline Christian & 235 & 6.3 & 5.7 & 2.8 & 17.2 & 74.22 & 100 & \\
\hline Islam & 5311 & 92.5 & 29.7 & 33.0 & 26.5 & 10.8 & 100 & \\
\hline Other & 73 & 1.2 & 28.8 & 21.1 & 40.7 & 9.4 & 100 & \\
\hline \multicolumn{9}{|l|}{ Education } \\
\hline None & 4425 & 76.4 & 30.8 & 35.5 & 26.2 & 7.5 & 100 & $<.0001$ \\
\hline Primary & 651 & 12.0 & 27.0 & 22.0 & 31.0 & 19.9 & 100 & \\
\hline Secondary+ & 543 & 11.6 & 11.4 & 10.8 & 20.6 & 56.1 & 100 & \\
\hline Wealth Index & & & & & & & & $<.0001$ \\
\hline Poorest & 2191 & 37.6 & 33.8 & 36.9 & 24.9 & 4.4 & & 00 \\
\hline Poorer & 1783 & 31.0 & 27.0 & 37.8 & 26.6 & 8.6 & & 00 \\
\hline Poor & 817 & 14.9 & 24.7 & 31.0 & 27.2 & 17.1 & & 00 \\
\hline Richer & 542 & 10.4 & 16.8 & 24.2 & 26.0 & 33.0 & & 00 \\
\hline Richest & 286 & 6.0 & 9.4 & 12.2 & 17.1 & 61.2 & & 00 \\
\hline
\end{tabular}




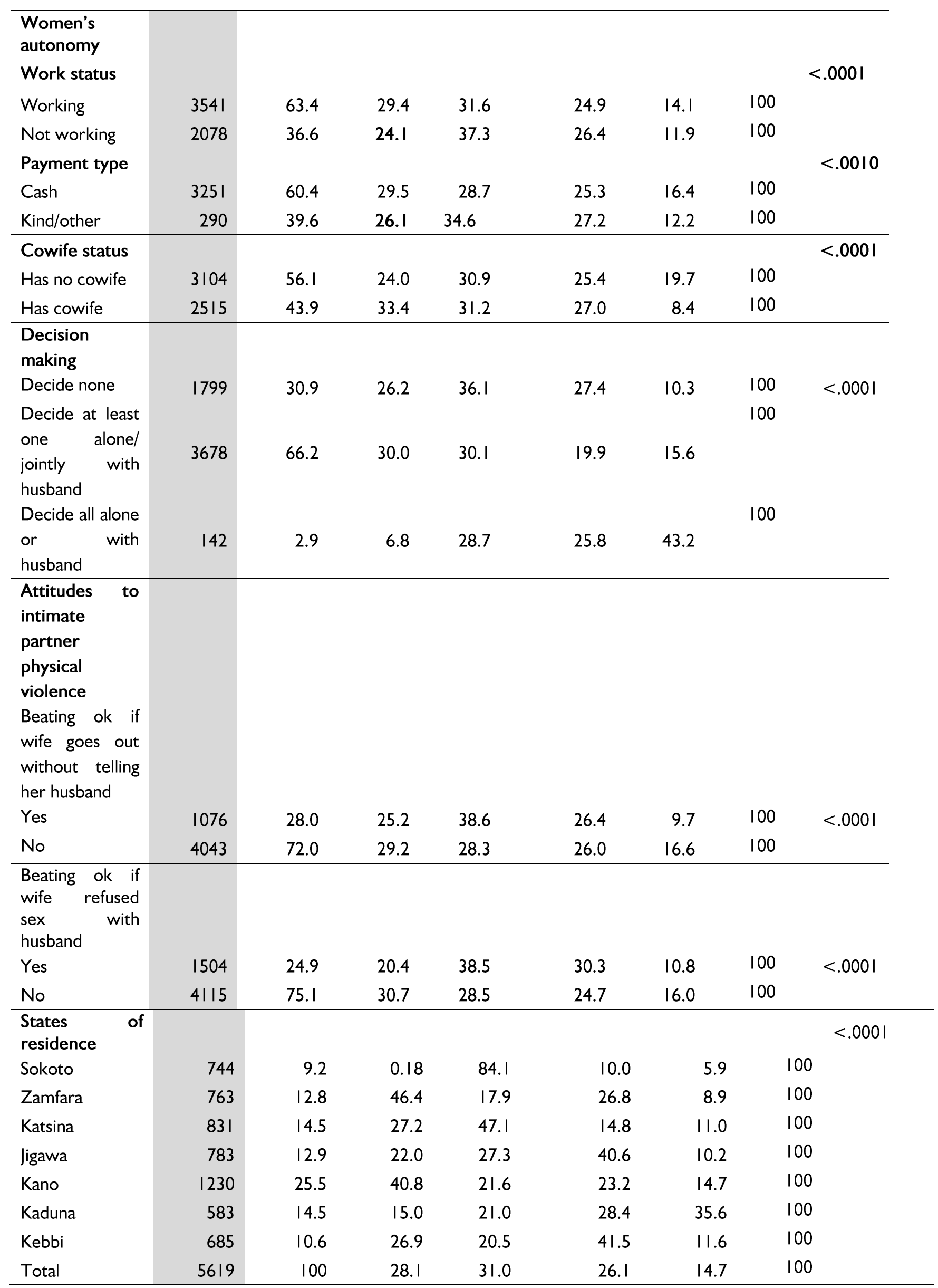

Table 4: Differences in health seeking practices between women who utilized NOP attendants and and those who delivered with SBA among women who had a live birth in 5 years preceding the survey, NW, Nigeria DHS 2013 3451 


\begin{tabular}{|c|c|c|c|c|c|c|}
\hline \multirow[t]{2}{*}{ Characteristic } & \multirow[t]{2}{*}{$\begin{array}{r}\text { Un- } \\
\text { weighted } \\
\mathrm{N}\end{array}$} & \multirow[t]{2}{*}{$\begin{array}{r}\text { Weighted } \\
\%\end{array}$} & \multicolumn{4}{|c|}{$\begin{array}{l}\% \text { of women who utilized } \\
\text { specific types of birth attendant } \\
\text { in their most recent deliveries }\end{array}$} \\
\hline & & & NOP & SBA & Total & $\mathrm{x}^{2}$ \\
\hline \multicolumn{7}{|l|}{ Contraceptive use } \\
\hline No Method & 2312 & 92.4 & 70.5 & 29.5 & 100 & $<.0001$ \\
\hline Any method & 138 & 7.6 & 13.3 & 80.7 & 100 & \\
\hline \multicolumn{7}{|l|}{ ANC visits during most recent delivery } \\
\hline 0 visits & 1161 & 45.1 & 91.4 & 8.6 & 100 & $<.0001$ \\
\hline I-4 visits & 650 & 26.6 & 53.9 & 46.1 & 100 & \\
\hline $5+$ & 639 & 28.3 & 37.3 & 62.7 & 100 & \\
\hline \multicolumn{7}{|l|}{$\begin{array}{l}\text { Mothers were checked following } \\
\text { delivery }\end{array}$} \\
\hline Checked & 756 & 32.4 & 11.4 & 88.6 & 100 & $<.0001$ \\
\hline Not Checked & 1694 & 67.6 & 92.3 & 7.7 & 100 & \\
\hline \multicolumn{7}{|l|}{ Time mothers put baby to the breast } \\
\hline Immediately, within I hour & 640 & 27.6 & 46.5 & 53.5 & 100 & $<.0001$ \\
\hline Hours later & 989 & 41.3 & 69.2 & 30.8 & 100 & \\
\hline Days later & 821 & 31.1 & 81.0 & 19.0 & 100 & \\
\hline \multicolumn{7}{|l|}{$\begin{array}{l}\text { Children fed food/drinks other than } \\
\text { breast milk in I st } 3 \text { days of live }\end{array}$} \\
\hline \% Fed Nothing & 796 & 33.5 & 55.1 & 44.9 & 100 & $<.0001$ \\
\hline$\%$ Fed something & 1654 & 66.5 & 71.6 & 28.4 & 100 & \\
\hline \multicolumn{7}{|l|}{$\begin{array}{l}\text { Children } \mathrm{U} 5 \text { slept under ITN in night } \\
\text { before the survey }\end{array}$} \\
\hline Slept under ITN & 435 & 18.2 & 60.5 & 39.5 & 100 & $<.0001$ \\
\hline Did not sleep under ITN/No net & 1150 & 45.9 & 69.8 & 30.2 & 100 & \\
\hline No Net & 782 & 35.9 & 63.7 & 36.3 & 100 & \\
\hline \multicolumn{7}{|l|}{ Health card ownership } \\
\hline Health card was seen /reported & 664 & 30.1 & 31.6 & 68.4 & 100 & $<0001$ \\
\hline Neven had a card/no longer has card & 1786 & 69.9 & 81.0 & 19.0 & 100 & \\
\hline \multicolumn{7}{|l|}{ Home management of fever in U5 } \\
\hline Had fever & 323 & 13.2 & 62.1 & 37.9 & 100 & .126 \\
\hline NO fever & 2127 & 86.8 & 66.7 & 33.3 & 100 & \\
\hline $\begin{array}{l}\text { Of those treated, \% treated at public } \\
\text { health facilities }\end{array}$ & 106 & 49.1 & 59.0 & 41.0 & 100 & $<.0001$ \\
\hline$\%$ treated at Shop/mkt//PMS & 93 & 42.8 & 74.4 & 25.6 & 100 & $<.0001$ \\
\hline$\%$ treated at traditional healers/other & 10 & 4.2 & 84.4 & 15.6 & 100 & .1090 \\
\hline \multicolumn{7}{|l|}{ Home management of diarrheal in U5 } \\
\hline$\%$ had diarrheal & 272 & 11.4 & 64.1 & 35.9 & 100 & .6390 \\
\hline$\%$ No diarrheal & 2178 & 88.6 & 66.4 & 33.6 & 100 & \\
\hline $\begin{array}{l}\text { Of those sick with diarrheal, } \% \text { gave } \\
\text { antibiotics }\end{array}$ & 71 & 26.1 & 39.4 & 60.6 & 100 & $<.0001$ \\
\hline$\%$ received no antibiotics & 201 & 73.9 & 73.1 & 26.9 & 100 & \\
\hline Total & 2450 & 100 & 66.1 & 33.9 & 100 & 100.0 \\
\hline
\end{tabular}


Table 5: Adjusted odds ratios predicting exposure to hazardous maternal and newborn health practices by women who delivered with NOP versus those who delivered with any attendants among those who had a live birth in 5 years preceding the survey, Nigeria DHS 2013*

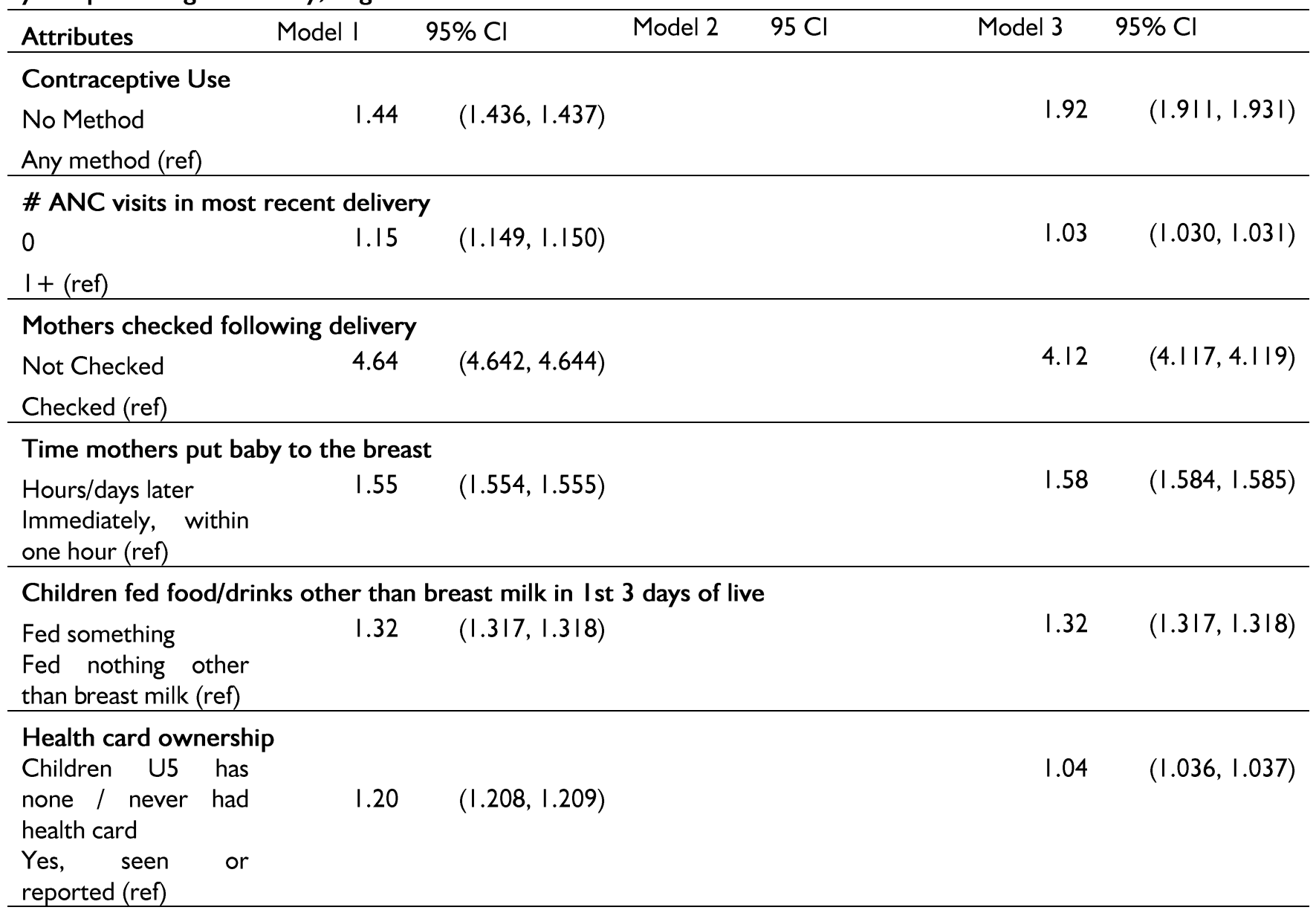

Children U5 slept under ITN in night before the survey
No Net
$1.15 \quad(1.154,1.156)$
1.18
$(1.179,1.180)$

Other groups (ref)

Home management of diarrhea in children $<5$ years

Children U5 had

$1.71 \quad(1.709,1.710)$

diarrhea in 2 wks.

$1.68(1.682,1.683)$

before survey

Children U5 had no

diarrhea (ref)

Children got no

antibiotics for

diarrhea

for $\quad 2.28 \quad(2.282,2.285)$

$2.13 \quad(2.134,2.135)$

Got antibiotics (ref)

Women's autonomy

Women working

Women work and

receives cash for

work

Not working/working

not receiving cash

(ref)

\section{Decision making}

Not involved in any

decision making

Involved in all or

some of the

$.95 \quad(.954, .955) \quad .92 \quad(.916, .917)$


measured decisions

(ref)

\section{Attitudes towards intimate partner physical violence}

Beating okay if wife

$1.14 \quad(1.135,1.140) \quad 1.14 \quad(1.137,1.138)$

goes out without

telling her husband

Beating not okay if

wife goes out

without telling... (ref)

Beating okay if wife

refused sex with

.59

$(.588, .588)$

.544

$(.544, .544)$

husband

Beating not okay if

wife refused sex with

husband (ref)

\section{Co-wife status \\ Has at least one \\ cowife \\ Has no cowife (ref)}

$1.16 \quad(1.162,1.163)$

1.16

$(1.159,1.160)$

\section{Socioeconomic determinants \\ Children ever born \\ (ceb)}

\section{Education}

None

$1.47 \quad(1.474,1.475) \quad 1.11 \quad(1.113,1.114)$

Primary School only

$1.48 \quad(1.483,1.484) \quad 1.23 \quad(1.236,1.237)$

Secondary or higher (ref)

\section{Religion}

Islam

2.42

$(2.424,2.426$

2.10

$(2.104,2.106)$

Christian/other (ref)

\section{Wealth Index}

Poorest

2.92

$(2.924,2.925)$

2.02

$(2.019,2.020)$

Poorer

2.02

$(2.015,2.017)$

1.52

(1.527, I.528)

Poor

$1.94 \quad(1.944,1.946)$

1.63

$(1.630,1.631)$

Rich/richer categories

(ref)

\section{Residence}

Rural

.88

$(.885, .886)$

.94

$(.936, .940)$

Urban (ref)

Age

$$
\text { 15-19 (Ref) }
$$

20-24

25-29

$1.67(1.669,1.670)$

$1.41 \quad(1.405,1.406)$

1.38

$(1.380,1.381)$

30-34

2.33

(2.329, 2.331)

1.39

I.397, 1.398)

1.33

$(1.329,1.330)$

$35+$

$3.04 \quad(3.048,3.050)$

1.32

$(1.323,1.324)$

1.26

$(1.259,1.260)$

States of residence

3.37

$1.12 \quad(1.119,1.120)$

1.07

$(1.069,1.070)$

Zamfara

Katsina

Jigawa

$\begin{array}{ll}644.41 & (643.203 \\ & 645.616) \\ 247.17 & (246.713 \\ 247.637) \\ & (191.889 \\ 192.25 & 192.609)\end{array}$

$\begin{array}{ll}504.46 & (503.521, \\ & 505.409) \\ 212.16 & (211.766, \\ & 212.560) \\ 172.79 & (172.471, \\ & 173.118)\end{array}$

504.46 (503.52I,

$212.16 \quad(211.766$

(172.47|,

(73.118)
596.24 (595.119, 597.354)

208.64 (208.244, 209.026)

184.67 (I84.321, 
African Population Studies Vol. 3I, No. I,(Supp.), 2017

$\begin{array}{lllllll}\text { Kano } & & (500.941, & 506.10 & (505.155, & 507.74 & (506.790, \\ & 501.88 & 502.817) & & 507.047) & & 508.689) \\ \text { Kaduna } & & (191.502, & 226.20 & (225.774, & 261.61 & (261.120, \\ \text { Kebbi } & 191.86 & 192.222) & & 226.624) & & 262.103) \\ & & (212.620, & 265.00 & (264.500, & 256.62 & (256.138, \\ & 213.02 & 213.419) & & 265.494) & & 257.101)\end{array}$

Sokoto (ref)

* all estimates significant at .01 alpha level; $\mathrm{N}=5,619$.

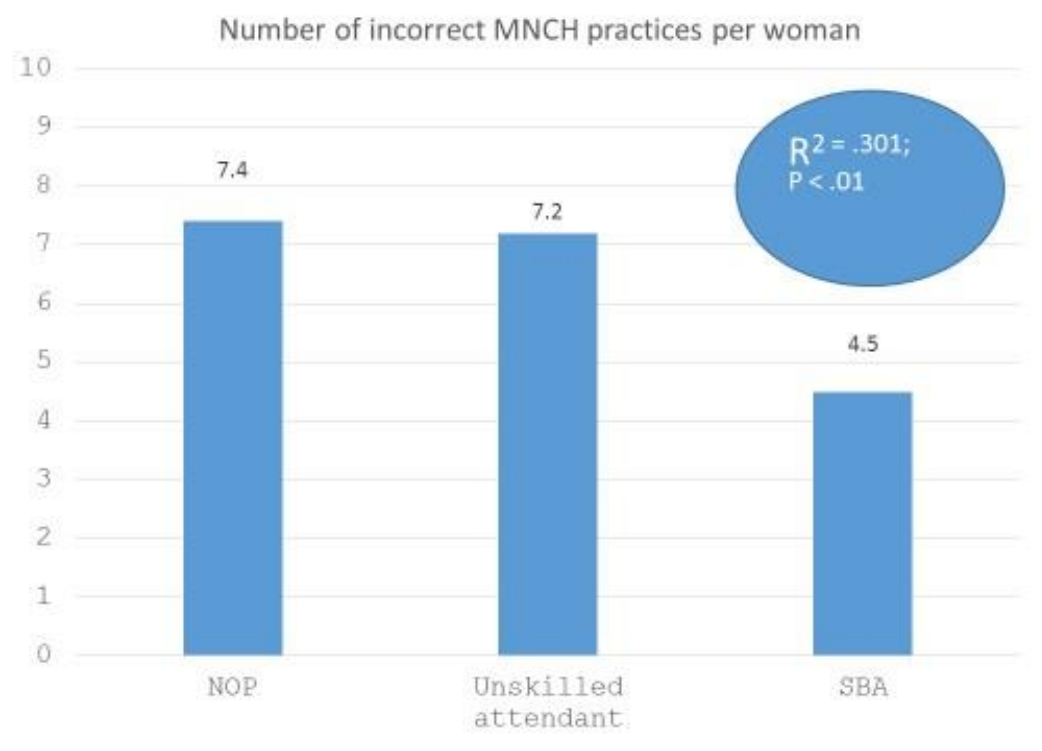

Figure I: Differentials in the intensity of risk among women by type of delivery attendants utilized in most recent deliveries among women who had a live birth in 5 years preceding the survey, NDHS 2013

$\mathrm{N}=5,619$ women of reproductive age who had a birth in 5 years preceding NDHS 2013 . 